\title{
AGUA QUE SOBRA, AGUA QUE FALTA. LAS FUENTES PÚBLICAS Y LA SOCIABILIDAD DEL AGUA EN LA CIUDAD DE MÉXICO, 1770-1818
}

\author{
Rebeca López Mora \\ Universidad Nacional Autónoma de México
}

A lo largo de su historia, la ciudad de México ha demandado lugares cercanos (o a veces no tanto). A finales del siglo xviII y principios del xix la ciudad dependía del agua limpia que entraba por los acueductos de Chapultepec y Santa Fe, la cual se distribuía entre la población por medio de conductos subterráneos llamados ramos de agua. ${ }^{1}$ Estos conductos contaban con fuentes públicas y privadas que llevaban hacia la superficie el agua que utilizaba la población de la capital.

Existen varios estudios acerca de las fuentes de agua, entre los que destacan los de Manuel Romero de Terreros; ${ }^{2}$ Alan Musset; ${ }^{3}$ Marcela Dávalos; ${ }^{4}$ Sonia Lombardo, Guadalupe de la Torre, María Gayón y María Dolores Morales, ${ }^{5}$ y María del Carmen León García. ${ }^{6}$ Si bien en cada uno de ellos se presenta la importancia

Fecha de recepción: 21 de octubre de 2019

Fecha de aceptación: 30 de marzo de 2020

1 Orozco y Berra, “La ciudad de México”, p. 114.

2 Romero de Terreros, Fuentes virreinales.

${ }^{3}$ Musset, El agua en el Valle de México.

${ }^{4}$ Dávalos, Los letrados.

${ }^{5}$ Lombardo, De La Torre Villalpando, Gayón Córdoba y Morales MARTínez, Territorio y demarcación.

${ }^{6}$ León García, "Las fuentes de agua y las plazas públicas". 
de las fuentes para el funcionamiento de la ciudad y los inconvenientes que ocasionaba a su población la falta del suministro del líquido en diversas épocas, en ninguno de ellos se relaciona el espacio, los pobladores y el número de fuentes públicas y privadas para comprender el funcionamiento de la sociedad capitalina. Los datos del número de las fuentes se exponen sin dar fechas o contextos. ${ }^{7}$ Podría pensarse que el número de éstas fue siempre el mismo, pero no fue así. Las ciudades de Antiguo Régimen realizaron diversas obras para la distribución del agua, en especial acueductos y fuentes. La ciudad de México contó con fuentes públicas y privadas desde el siglo xvi, siguiendo el modelo de distribución que había en España. Por ejemplo, Madrid contaba en 1632 con 173 fuentes particulares y 26 públicas que distribuían agua proveniente de manantiales ubicados a las afueras de la ciudad. ${ }^{8}$ Por su parte, en 1616 la ciudad de México contaba con 37 fuentes públicas, aunque sólo funcionaban 17 , así como otras tantas fuentes privadas. ${ }^{9}$

Este estudio comprende de 1770 a 1818, periodo marcado por la implementación de políticas ilustradas que buscaron hacer más eficiente la administración pública de la ciudad. Existen muchísimas referencias documentales de las medidas que tomó el Ayuntamiento, así como el propio virrey para subsanar las necesidades de agua de los pobladores de la ciudad. Las visitas a las fuentes, las mediciones del agua de éstas y de los acueductos, así como las obras públicas emprendidas para dar un mejor servicio de dotación de agua nos permiten vislumbrar el día a día de la ciudad. Para entender la función de las fuentes públicas y privadas durante ese periodo se consideró necesario relacionar dos variables: la población y el número de fuentes. Esta relación

\footnotetext{
7 Por ejemplo, en el texto de Pineda, Origen, p. 48, menciona que durante la colonia el acueducto de Chapultepec tenía 25 fuentes particulares y 5 públicas, pero no menciona la fecha, por lo cual el dato carece de exactitud.

${ }_{8}$ Pinto, Los viajes de agua de Madrid, p. 63.

9 AC, 28 de noviembre de 1616.
} 
permite hacer una nueva lectura de la ocupación del espacio urbano, así como ponderar el papel que tuvieron las fuentes públicas en la ciudad.

Para realizar este trabajo se contó con una muy valiosa información proveniente del Archivo Histórico de la Ciudad de México. Las continuas quejas de la población por la falta de agua en las fuentes, así como los continuos abusos de quienes contaban con una merced de agua para uso particular, obligaron a las autoridades a realizar continuas supervisiones a las datas (o cavidades) por donde se surtía el agua, lo cual generó muchísima información documental. Estos datos se encuentran en las actas de Cabildo, así como en el fondo Ayuntamiento, secciones Aguas. Fuentes Públicas; Aguas. Documentos diversos para el arreglo del Ramo; Aguas. Reconocimiento de las mercedes de los cuarteles; Aguas. Rios y Acequias; Aguas. Santa Fe y los Leones. Estos datos se utilizaron siempre en referencia a las zonas que se identificaron con el factor fuentes/pobladores, para darles un contexto social que permitiera hacer su correcta valoración dentro del espacio urbano. Por lo que respecta a los datos demográficos, se utilizó el cuadro insertado en el libro de Alejandro de Humboldt Ensayo político de la Nueva España referente al censo de $1816 .{ }^{10}$ Esta información es presentada en un cuadro que contiene el total de población en cada uno de los 32 cuarteles menores.

La relación de las fuentes públicas y privadas que utilizamos fue recopilada en 1818 en los ocho cuarteles mayores. Nos dimos a la tarea de ubicar cada una de ellas en los cuarteles menores, y para ello fue necesario ubicar cada calle en el cuartel menor por medio de dos herramientas: la primera fue la ubicación geográfico espacial, para lo cual utilizamos el plano de García Conde elaborado en 1793 y copiado en 1811. La segunda

${ }^{10}$ Humboldt, Ensayo político, p. 131. Este cuadro fue incluido por el editor de ese texto en 1822. 
herramienta fue la ubicación de las calles dentro de cada cuartel menor, y para ello se consultó el libro México dividida en quarteles mayores y menores publicado en $1811 .^{11}$

Este estudio consta de las siguientes partes. La primera presenta la ubicación de los acueductos que surtían de agua a la ciudad, así como su distribución en las fuentes a través de los conductos subterráneos, denominados ramos de agua. En la segunda parte se muestra el factor fuentes sobre población para identificar las cuatro zonas en que se dividió la ciudad. En el tercer apartado se hablará de cada una de las zonas de distribución y de los problemas que enfrentó la población en cada una de ellas.

\section{LAS ENTRADAS DE AGUA: LOS ACUEDUCTOS \\ DE SANTA FE Y CHAPULTEPEC}

El agua consumida en la ciudad de México provenía de dos acueductos, el de Santa Fe y el de Chapultepec. El primero conducía el agua que nacía en un manantial ubicado en las inmediaciones del pueblo de Santa Fe, caudal al que se unía el que venía desde el Desierto de los Leones. ${ }^{12}$ Esta agua entraba por un conducto abierto por la Avenida de la Verónica (hoy Circuito Interior) hasta San Cosme, y de ahí doblaba hacia el centro de la ciudad, hasta llegar a la fuente de la Mariscala, a espaldas del actual Palacio de Bellas Artes. Orozco y Berra afirmaba que de esta agua se abastecían dos tercios de la ciudad, "comprendidos entre la garita de Peralvillo y la línea de este a oeste que comienza en la Candelaria y termina en la calle de Alconedo". ${ }^{13} \mathrm{El}$ conducto del Desierto de

\footnotetext{
11 El plano se encuentra en la Mapoteca Orozco y Berra. México dividida.

${ }_{12}$ El agua de Santa Fe llegó a la ciudad desde el siglo xvi, con la compra que hizo el Ayuntamiento del manantial que había en ese pueblo. El agua del Desierto de los Leones se incorporó a este acueducto en 1786, ante la creciente demanda de agua de la capital. Peñafiel, Memoria sobre las aguas potables, p. 17.

${ }^{13}$ Orozco y Berra, Memoria para la carta hidrográfica, p. 84 .
} 
los Leones atravesaba 24932 metros en cerros, montes y laderas, y se unía con el acueducto que conducía el agua del manantial de Santa Fe hasta su entrada a la capital por la calle de San Cosme. ${ }^{14}$

El acueducto de Santa Fe constaba de dos partes, una superior, que era la que conducía el agua delgada, y una inferior, que llevaba agua gorda procedente del Río de los Morales. Este último conducto recibía agua procedente del Río Hondo, desde la caja repartidora ubicada en el actual municipio de Naucalpan, en el Estado de México. ${ }^{15} \mathrm{El}$ agua delgada era considerada la de mejor calidad, debido a que tenía menos materias pesadas, o fijas según Antonio Peñafiel, y a decir de este mismo, tenía un sabor más agradable. ${ }^{16}$

Al llegar a la fuente de la Mariscala, se introducía en una caja de distribución, de la cual derivaban cuatro ramos subterráneos de distribución: los de la Santísima y Palacio (que iban por debajo de cada una de las aceras de la calle Tacuba), el de San Lorenzo (hacia la parte norte de la Mariscala, y que doblaba hacia el centro por el convento de San Lorenzo) y el ramo de San Francisco (que corría por la calle de Santa Isabel (hoy Hidalgo), hacia el puente de San Francisco (hoy Eje Central), y de ahí doblaba por la calle San Francisco (hoy Madero), hasta la calle Don Juan Manuel (hoy Venustiano Carranza).

El otro acueducto que surtía a la ciudad era el de Chapultepec, que nacía en un manantial conocido como la Alberca Chica, ubicado al pie del cerro del mismo nombre, ${ }^{17}$ y que según Viera estaba en el Real Alcázar. ${ }^{18}$ El agua se transportaba a la ciudad por un acueducto abierto de una longitud de 3907 metros $^{19}$ hasta

\footnotetext{
${ }_{14}$ Peñafiel, Memoria sobre las aguas potables, p.8.

15 AHCM, AARA, vol. 3876, exp. 266, f. 29.

16 Peñafiel, Memoria sobre las aguas potables, pp. 2 y 4.

17 Pineda, Origen, vida y muerte, p. 34.

${ }_{18}$ VIERA, Breve y compendiosa narración, p. 96.

19 Peñafiel, Memoria sobre las aguas potables, p. 8. Los datos acerca de la distancia varían entre los autores. Por ejemplo, Нumbodlt, Ensayo político
} 
entrar a la ciudad por el sur, y remataba en la fuente del Salto del Agua. La construcción de este acueducto se terminó en marzo de 1779..$^{20}$ A este líquido se le conocía como "agua gorda” porque venía muy cargada de minerales, los cuales la hacían de menor calidad. Humboldt afirmaba que el agua gorda era la que consumían los arrabales, cosa no totalmente cierta. ${ }^{21}$ En realidad, la distribución de agua gorda cubría la zona sur de la ciudad y algunas calles del centro, por el cuartel menor 9 (ubicado cerca del Hospital de Jesús). Esta agua la recibían barrios pobres, así como distinguidas instituciones, como el Colegio de las Vizcaínas. De este acueducto derivaban tres conductos subterráneos, llamados ramos, a saber, los del Bosque (o Alameda), San Pablo y Merced.

El sistema de distribución del agua de la ciudad tenía una tecnología con base en la gravedad y corría de poniente a oriente y de sur a norte. Esto se tradujo en un funcionamiento deficiente, y de ello daba testimonio Tadeo Ortiz en la década de 1830, al observar que "el corto declive y ninguna pendiente del piso de la capital, dificulta[ba] el curso de las aguas de las atargeas [...]".22 Ésta fue una de las razones por las cuales los caños subterráneos no pudieron llevar agua a diversas zonas del oriente, sur y norte de la ciudad. ${ }^{23}$ Por si fuera poco, estos conductos sufrieron muchos destrozos a causa del material con el que estaban hechos. En 1731 comenzaron a sustituirse los caños de plomo por los de barro, por considerarse que eran más adecuados para la salud. El caño era cilíndrico, con una boca convexa y otra cóncava, para ser ensamblados uno tras otro, unidos con zulaque. ${ }^{24}$ En 1790 se

afirmaba que el acueducto de Chapultepec medía 3300 metros.

20 Rivera y Cambas, México pintoresco, p. 243.

21 Humboldt, Ensayo político, p. 120.

22 Ortiz, México considerado, p. 513.

23 Según el Diccionario de Autoridades, un caño era un instrumento hueco, redondo y largo, hecho de metal, vidrio o barro, a modo de caña, para que lo líquido pueda correr sin desperdiciarse. En general, se hablaba de los caños subterráneos por donde corría el agua a lo largo de la ciudad.

24 Gaceta de junio de 1731, Gaceta de México, vol. 1, pp. 334-335. 
ordenó que estas cañerías se ubicaran debajo de las aceras, para que no sufrieran más que el peso de la gente, y con ello evitar hundimientos que rompieran el suministro. Se reiteró que debían estar construidos de barro colado, bien cocido y vidriado, y pegados con zuloague ${ }^{25}$ bien amasado, para evitar que la porosidad trajera pérdidas de agua o presencia de insectos nocivos. ${ }^{26}$ No obstante estas indicaciones, alrededor de 1790 las cañerías estaban "casi enteramente arruinadas [...]" de acuerdo al informe que dio el segundo Conde de Revillagigedo a su sucesor.

\section{Plano 1}

LOS RAMOS SUBTERRÁNEOS DE DISTRIBUCIÓN DE AGUA, 1818

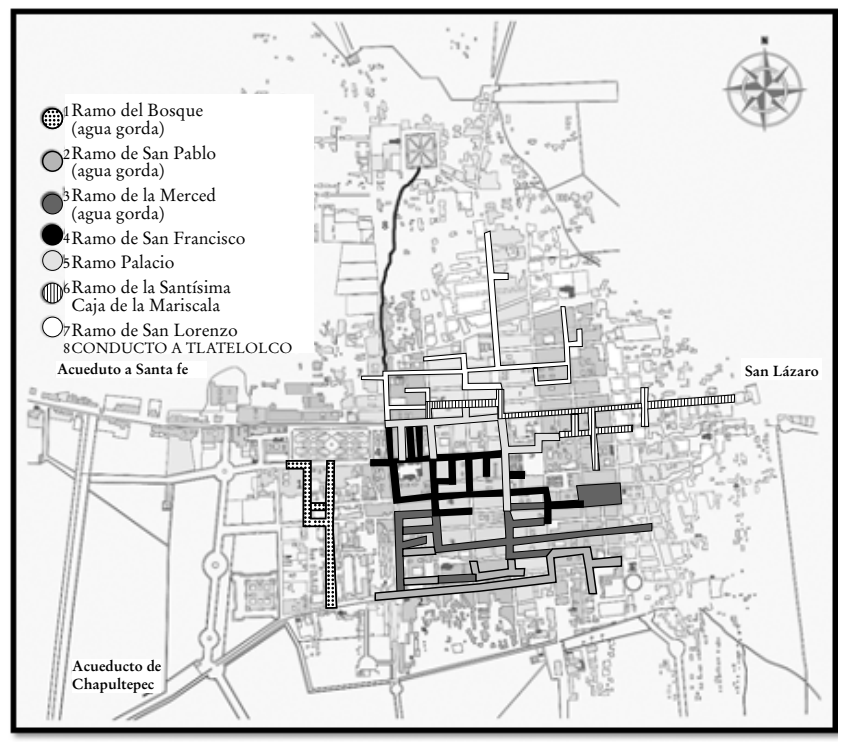

FuENTE: elaboración propia con base en los datos de la visita de 1818 y en el plano de García Conde.

${ }^{25}$ AHCM, $A F P$, vol. 58, exp. 25, f. 43. El zulaque o zuloague se componía de pelo de cabra batido con manteca de puerco ordinario, aceitillo y polvo de cal viva.

${ }^{26}$ Revillagigedo, Instrucción reservada, p. 75. 
El Ayuntamiento de la ciudad tenía la responsabilidad de dotar de agua a los ciudadanos a través de fuentes públicas o privadas. Estas últimas se obtenían por medio de mercedes concedidas a particulares, por diversos medios. Una de ellas era el pago de 500 pesos por cada paja de agua, que era la medida que generalmente era utilizada en repartos particulares. Los beneficiarios debían conectarse por medio de caños que llevaba el líquido a fuentes ubicadas en el interior de sus casas. ${ }^{27}$ Otro medio por el cual los particulares podían obtener mercedes de agua fue ocupando puestos públicos. En 1787, el procurador general de la ciudad recordó que las Ordenanzas de Agua de 1710 indicaban que los ministros togados, el corregidor y los regidores, tenían derecho a mercedes de agua. Eso implicaba que si la obtenían, y luego cambiaban de domicilio, podían llevarse el derecho a su nuevo lugar de residencia, siempre que éste fuera dentro de la ciudad. ${ }^{28}$ Estas personas estaban exentas de pagar los derechos correspondientes.

El Ayuntamiento de la ciudad recibía continuas quejas de los vecinos por la falta de agua en las fuentes. Los miembros del cabildo estaban conscientes de que era su responsabilidad surtir de agua a los vecinos de la ciudad, según se observa en un informe realizado en 1796:

El abasto de aguas en todas las ciudades y poblaciones del orbe es, y ha sido siempre, uno de los objetos más necesarios y recomendables, ha merecido en esta Capital la más particular atención de los Soberanos, de todos los Superiores, y de esta Nobilísima Ciudad, que se ha desvelado continuamente para conseguir el mejor servicio público en esta parte, invirtiéndose para ello numerosos caudales,

27 Aunque este dato corresponde a 1801, la misma cuota permaneció prácticamente todo el siglo xviI y por lo menos hasta la segunda década del xIx. AHCM, $A A D R$, vol. 30, exp. 29, f. 8. Una paja de agua equivale a un cuartillo o libra por minuto, que en sistema métrico decimal representa 0.00075 litros por segundo. Palerm y Chávez, "Medidas antiguas...", pp. 230 y 236.

28 AHCM, $A A D R$, vol. 29, exp. 2, f. 7. 
y dictándose las más sabias providencias [...] A pesar de estos desvelos, y de los deseos que animan para el mejor arreglo en el repartimiento de las Aguas, no han dejado de sentirse en estos últimos tiempos algunos perjuicios, que aunque no lleguen al grado de padecerse falta o escasez considerable, no deja de sufrirse quebranto que exige el remedio oportuno $[\ldots]{ }^{29}$

Por supuesto que hubo tiempos en que se sufría gran escasez, o incluso falta de agua en la ciudad. El mismo hecho de conducir el agua a lo largo de muchos kilómetros hasta su llegada a la ciudad, favorecía el abuso por parte de los que aprovechaban el caudal antes de su entrada a la urbe. Pero también la distribución del agua en el casco urbano, por medio de los ramos de agua basados en el sistema de gravedad, fue ineficiente. Por si fuera poco, la ubicación de las fuentes públicas y privadas fue desigual en el espacio urbano, lo que determinó, en muchos casos, una distribución inequitativa, como se verá a continuación.

\section{FUENTES Y POBLACIÓN: \\ EL FACTOR DE DIFERENCIACIÓN SOCIAL DEL AGUA}

Como se ha mencionado, los datos que nos permiten hacer una zonificación de la ciudad en lo que respecta a la distribución de agua, provienen de un estudio que se levantó en 1818, en el cual se revisaron las fuentes públicas y privadas de los ocho cuarteles mayores de la ciudad de México. Durante el siglo XVII estas visitas se hacían periódicamente para verificar que los mercedados pagaran los derechos respectivos. Sin embargo, la visita de 1818 es muy precisa, y aporta gran cantidad de datos. Se identificaron las fuentes privadas, que eran aquellas ubicadas en casas particulares, en casas habitadas por comunidades, en vecindades y en edificios dedicados a una actividad comercial.

29 AHCM, $A A D R$, vol. 30, exp. 28. 
También las fuentes públicas y otros datos importantes, como el origen de la merced, la distancia entre el ramo de distribución y la fuente, el dueño o arrendatario del inmueble, y la cantidad de fuentes ubicadas en las casas. En nuestro estudio sólo se contó una fuente por cada toma particular, para evitar confusiones y poder hacer una contabilidad adecuada. Los datos obtenidos nos muestran una gran diferencia en el número de fuentes entre cuarteles menores, lo que nos permite distinguir las diversas zonas de la ciudad, como se observa en el siguiente cuadro.

\section{Cuadro 1}

FUENTES PÚBLICAS Y PRIVADAS, 1818

\begin{tabular}{|c|c|c|c|}
\hline Cuartel menor & Total fuentes & Públicas & Privadas \\
\hline 1 & 48 & 0 & 48 \\
3 & 14 & 0 & 14 \\
4 & 2 & 0 & 2 \\
5 & 52 & 2 & 50 \\
6 & 7 & 2 & 5 \\
7 & 17 & 2 & 15 \\
9 & 12 & 0 & 12 \\
10 & 7 & 0 & 7 \\
11 & 14 & 0 & 14 \\
12 & 1 & 0 & 1 \\
13 & 13 & 0 & 13 \\
14 & 25 & 1 & 24 \\
16 & 1 & 0 & 1 \\
17 & 7 & 3 & 4 \\
21 & 13 & 3 & 10 \\
22 & 2 & 2 & 0 \\
23 & 1 & 0 & 1 \\
24 & 38 & 4 & 34 \\
25 & 10 & 2 & 8 \\
26 & 3 & 0 & 3 \\
28 & 6 & 3 & 3 \\
29 & 5 & 2 & 3 \\
30 & 8 & 0 & 8 \\
31 & 13 & 1 & 12 \\
32 & 10 & 28 & 9 \\
Totales & 329 & $A$ & 91 \\
\hline
\end{tabular}

FuENTE: elaboración propia con base en AHCM, $A A D R$, vol. 29, exp. 15; y AHCM, $A A D R$, vol. 30, exp. 2. 
Como se puede observar, no todos los cuarteles menores contaban con fuentes de agua. Sin embargo, el dato del número de fuentes por cuartel resulta insuficiente para distinguir las zonas de menor y mayor distribución de agua. Por ello se estableció un factor que se deriva de la relación entre el número de fuentes y el número de pobladores de cada cuartel menor. Como se ha mencionado, para establecer esta relación se utilizaron los datos demográficos obtenidos en 1816 por el Ayuntamiento, y que fueron incorporados a la obra de Humboldt por su editor. ${ }^{30}$

En el cuadro 2 se ordenaron los datos del número de pobladores sobre el número de fuentes, con lo cual se pueden identificar zonas con mayor número de personas por fuente y en cambio otras con total carencia de fuentes de distribución. Si bien los datos se recabaron con base en un criterio administrativo (cuarteles mayores y menores), esto no necesariamente significó que los pobladores de cada cuartel solamente pudieran recurrir al agua de las fuentes de su demarcación. Sin embargo, considero que este factor, con base en datos administrativos, es la única forma en que podemos identificar zonas diferenciadas en la ciudad con base en un criterio hídrico.

Para identificar las zonas de abundancia, consideramos aquellos cuarteles menores que tenían menos de 350 personas por cada toma de agua. Determinar este factor fue una decisión muy difícil ya que no hay estudios que utilicen algo semejante a lo que aquí se propone. Sin embargo, nuestro criterio se formó considerando que el promedio de personas por fuente (tomando sólo en cuenta

30 Humboldt, Ensayo político, p. 130. Es necesario mencionar que en esta lista, así como en las "Tablas estadísticas del Reyno de Nueva España, 1813", Biblioteca Nacional de España, MSS/12968/31, se incluye una cantidad extra de personas censadas por los gobernadores de San Juan y de Tlaltelolco. Coincido con la opinión de Andrés Lira, en el sentido de que estos datos probablemente incluyeron a pobladores que vivían en pueblos dependientes de las parcialidades, pero fuera del casco urbano, ya que ambas zonas se encontraban incluidas en los cuarteles de la ciudad. LiRA, Comunidades indigenas, p. 37. 


\section{Cuadro 2}

TOTALES DE FUENTES Y POBLACIÓN, 1816-1818

\begin{tabular}{|c|c|c|c|c|c|c|c|c|}
\hline $\begin{array}{l}\text { Cuartel } \\
\text { menor }\end{array}$ & Hombres & Mujeres & $\begin{array}{c}\text { Población } \\
1816\end{array}$ & \begin{tabular}{|c|} 
Fuentes \\
privadas \\
1818
\end{tabular} & $\begin{array}{c}\text { Fuentes } \\
\text { públicas } \\
1818\end{array}$ & \begin{tabular}{|c|} 
Total \\
fuentes \\
1818 \\
\end{tabular} & $\begin{array}{l}\text { Fuentes/ } \\
\text { población }\end{array}$ & Zona \\
\hline 24 & 814 & 1493 & 2307 & 34 & 4 & 38 & 60 & Abundancia \\
\hline 5 & 4159 & 5471 & 9630 & 50 & 2 & 52 & 185 & Abundancia \\
\hline 1 & 4612 & 6145 & 10757 & 48 & 0 & 48 & 224 & Abundancia \\
\hline 21 & 1202 & 1801 & 3003 & 10 & 3 & 13 & 231 & Abundancia \\
\hline 3 & 1543 & 2530 & 4073 & 14 & 0 & 14 & 290 & Abundancia \\
\hline 7 & 2025 & 3114 & 5139 & 15 & 2 & 17 & 302 & Abundancia \\
\hline 13 & 1819 & 2627 & 4446 & 13 & 0 & 13 & 342 & Abundancia \\
\hline 9 & 1820 & 2304 & 4124 & 12 & 0 & 12 & 343 & Abundancia \\
\hline 32 & 1423 & 2116 & 3539 & 9 & 1 & 10 & 353 & Intermedia \\
\hline 30 & 1201 & 1681 & 2882 & 8 & 0 & 8 & 360 & Intermedia \\
\hline 14 & 4492 & 6526 & 11018 & 24 & 1 & 25 & 440 & Intermedia \\
\hline 28 & 1362 & 1527 & 2889 & 3 & 3 & 6 & 481 & Intermedia \\
\hline 25 & 2271 & 2634 & 4905 & 8 & 2 & 10 & 490 & Intermedia \\
\hline 31 & 2904 & 3519 & 6423 & 12 & 1 & 13 & 494 & Intermedia \\
\hline 10 & 1740 & 2185 & 3925 & 7 & 0 & 7 & 560 & Intermedia \\
\hline 11 & 4608 & 4248 & 8856 & 14 & 0 & 14 & 632 & Intermedia \\
\hline 29 & 1469 & 1931 & 3400 & 3 & 2 & 5 & 680 & Intermedia \\
\hline 17 & 2795 & 3394 & 6189 & 4 & 3 & 7 & 884 & Intermedia \\
\hline 6 & 3030 & 4054 & 7084 & 5 & 2 & 7 & 1012 & Escasez \\
\hline 26 & 2409 & 2914 & 5323 & 3 & 0 & 3 & 1774 & Escasez \\
\hline 22 & 1634 & 1931 & 3565 & 0 & 2 & 2 & 1782 & Escasez \\
\hline 4 & 1672 & 1951 & 3623 & 2 & 0 & 2 & 1811 & Escasez \\
\hline 23 & 1327 & 2011 & 3338 & 1 & 0 & 1 & 3338 & Escasez \\
\hline 16 & 1438 & 1923 & 3361 & 1 & 0 & 1 & 3361 & Escasez \\
\hline 12 & 1761 & 2147 & 3908 & 1 & 0 & 1 & $\begin{array}{c}3908 \\
\operatorname{Sin}\end{array}$ & $\begin{array}{c}\text { Escasez } \\
\text { Total }\end{array}$ \\
\hline 2 & 2806 & 3948 & 6754 & 0 & 0 & 0 & $\begin{array}{l}\text { fuentes } \\
\text { Sin }\end{array}$ & $\begin{array}{c}\text { carencia } \\
\text { Total }\end{array}$ \\
\hline 8 & 1162 & 1026 & 2188 & 0 & 0 & 0 & $\begin{array}{l}\text { fuentes } \\
\text { Sin }\end{array}$ & $\begin{array}{c}\text { carencia } \\
\text { Total }\end{array}$ \\
\hline 15 & 1345 & 1945 & 3290 & 0 & 0 & 0 & $\begin{array}{l}\text { fuentes } \\
\text { Sin }\end{array}$ & $\begin{array}{c}\text { carencia } \\
\text { Total }\end{array}$ \\
\hline 18 & 954 & 1060 & 2014 & 0 & 0 & 0 & $\begin{array}{l}\text { fuentes } \\
\text { Sin }\end{array}$ & $\begin{array}{c}\text { carencia } \\
\text { Total }\end{array}$ \\
\hline 19 & 3414 & 3626 & 7040 & 0 & 0 & 0 & $\begin{array}{l}\text { fuentes } \\
\text { Sin }\end{array}$ & $\begin{array}{c}\text { carencia } \\
\text { Total }\end{array}$ \\
\hline 20 & 1488 & 1452 & 2940 & 0 & 0 & 0 & $\begin{array}{l}\text { fuentes } \\
\text { Sin }\end{array}$ & $\begin{array}{c}\text { carencia } \\
\text { Total }\end{array}$ \\
\hline 27 & 380 & 355 & 735 & 0 & 0 & 0 & fuentes & carencia \\
\hline Totales & 67079 & 85589 & 152668 & 301 & 28 & 329 & & \\
\hline
\end{tabular}

Fuente: elaboración propia, con los datos de Humboldt, Ensayo político, p. 130. AHCM, $A A D R$, vol. 29, exp. 15; AHCM, $A A D R$, vol. 30, exp. 2. 
aquellos cuarteles que tenían al menos una de ellas) es de 383. Quisimos identificar como la zona de abundancia aquellos cuarteles que tuvieran menos de $10 \%$ del promedio ya mencionado.

La zona intermedia se consideró de 351 a 1000 personas por fuente. La zona de escasez se ubicó en cuarteles con más de 1000 personas por fuente, y que al menos contaran con una de ellas. Como se observa en el cuadro, hubo demarcaciones con total carencia de fuentes, los cuales fueron catalogados como de total carencia. Cabe mencionar que los datos con los que contamos provienen, en su mayoría, de las zonas que tenían al menos una fuente de agua. Las zonas de carencia absoluta, si bien eran las más necesitadas, no contaron con la atención requerida por parte de las autoridades, y por ello generaron menos información. En realidad, y como ya se ha analizado, el sistema de gravedad impedía llevar el líquido a zonas alejadas de la llegada del agua. Esta situación tuvo consecuencias para el crecimiento de esas zonas, de lo cual se hablará más adelante.

Como se puede observar, la población que contaba con una o varias fuentes dentro de sus casas era muy reducida. Para los 152668 habitantes contabilizados en 1816, tan sólo había 333 fuentes públicas y privadas en la ciudad. De los 32 cuarteles menores, 27 tenían, al menos, una fuente en su territorio. A pesar de que las personas con fuentes privadas pagaban un alto costo por el servicio, estaban obligados a permitir el acceso al agua a quienes lo solicitaran. Desde 1535, se ordenó que "aquel que tuviera agua del caño en sus casas, hagan alcantarilla en la calle a sus puertas donde está la dicha agua para que los vecinos e indios la tomen de las dichas alcantarillas e se aprovechen della". ${ }^{31}$ Las comunidades religiosas con frecuencia aportaron su caudal para ayudar a su vecindario. Por ejemplo, en 1801, el Colegio de Porta Coeli, de los padres dominicos, contaba con una fuente de agua que servía tanto a éstos como "para utilidad

31 AHCM, AC, 4 de junio de 1535. 
del vecindario, que siempre logran proveerse de agua". ${ }^{32}$ Este mismo servicio se reportó en 1803, cuando al escasear el agua de la fuente pública del Carmen, la gente de ese barrio tuvo permiso para entrar al convento del mismo nombre y poder tomar agua de su fuente interior. ${ }^{33}$

\section{Plano 2}

ZONIFICACIÓN DE LA CIUDAD SEGÚN LA DISTRIBUCIÓN DE AGUA

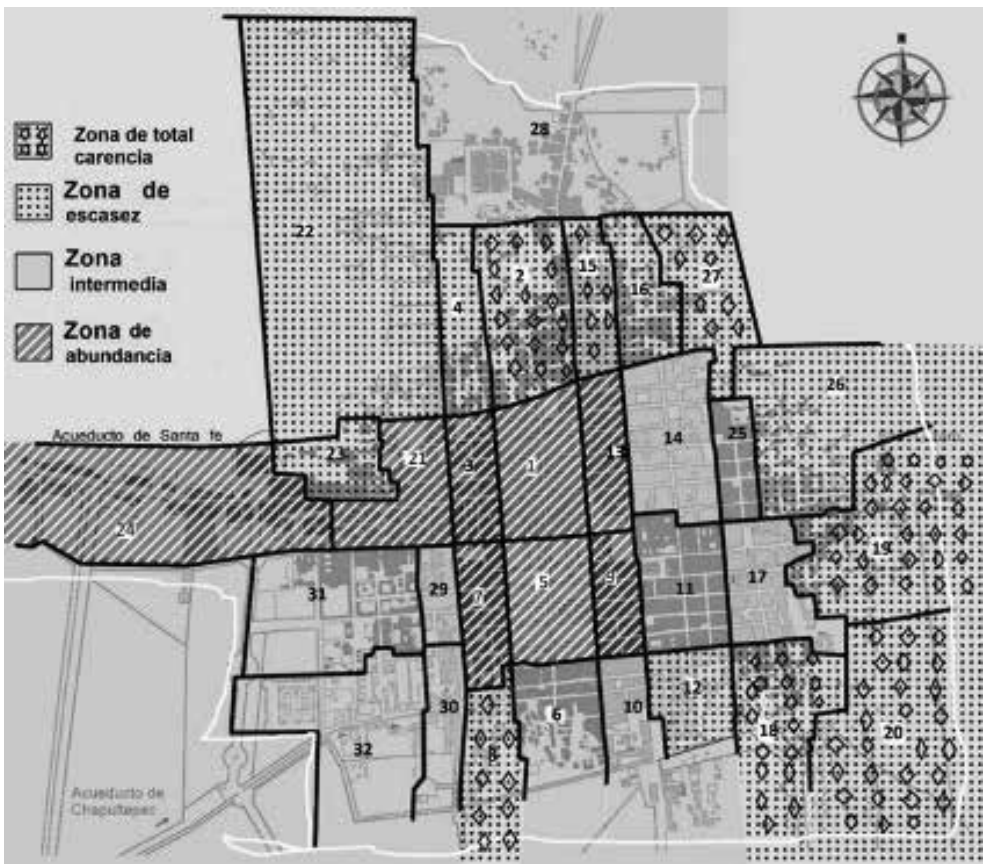

Fuente: elaboración propia con base en el plano de García Conde de 1793.

Las fuentes públicas aparecieron en la ciudad desde el siglo XVI. En el siglo XviII varias se mejoraron y otras más fueron

32 AHCM, $A A F P$, vol. 58, exp. 49, f. 4.

33 AHCM, $A P$, vol. 3629, exp. 135, f. 3 . 
construidas, como respuesta al crecimiento poblacional que se experimentó en esa centuria. El virrey segundo Conde de Revillagigedo señaló en sus Instrucción reservada, haber mandado edificar diez fuentes públicas con sus grifos, que buscaban evitar desperdicios. ${ }^{34}$ Algunas de las fuentes nuevas fueron proyectadas y edificadas por el famoso arquitecto Manuel Tolsá, quien en 1804 tenía el cargo de escultor de cámara honorario de Su Majestad. Como se sabe, este afamado arquitecto realizó obras tan importantes como el Colegio de Minería y la escultura de Carlos IV. Una de las fuentes realizadas por Tolsá fue la de Santa Catarina. ${ }^{35}$ Además, junto con el arquitecto mayor, don Ignacio Castera, fue autor del proyecto para ampliar el terreno de la Alameda y remozar el acueducto de Santa Fe, que corría en el lindero norte de este jardín público, así como para el mejoramiento de la caja de la Mariscala. Se ponderaban las magníficas obras de Tolsá diciendo que el plan modelo de la caja tendría "aquel primor que se admira en todas sus obras". ${ }^{36}$ Por su parte, don Ignacio Castera había tenido a su cargo la terminación de la pila nueva en la plazuela de Santo

${ }^{34}$ Revillagigedo, Instrucción reservada, p. 76. En 1788 se dio la orden de poner llave de bronce a cada una de las fuentes públicas y privadas, así como de imponer una multa de 200 pesos a las personas que se negaran a hacerlo. AHCM, $A A D R$, vol. 29, exp. 22, f. 11.

35 Es probable que este afamado escultor tuviera una relación especial con la zona, ya que a pesar de que no se mencionó esta fuente pública en los datos de 1818, se afirma que el famoso arquitecto había vivido en lo que en ese momento era el Baño de la Cerbatana y que pertenecía al convento de Santa Catarina. AHCM, $A A R M$, vol. 168, exp. 3, f. 4. Su viuda se mudó después a la calle del Puente de Alvarado y contó con una fuente particular. AHCM, $A A R M$, vol. 168, exp. 4, f. 1, 37 y 38 . Es probable que recibiera la merced de agua por los servicios prestados a la ciudad, tal y como se hizo con otros personajes ligados a la administración pública.

${ }^{36}$ Esta obra se hizo para dar un mejor conducto al aumento de agua que se experimentó con la llegada del líquido proveniente del Desierto de los Leones y que se juntó a la que venía de Santa Fe. AGN, OP, vol. 37, exp. 15, f. 217 y ss. 
Cuadro 3

FUENTES PÚBLICAS EN 1818

\begin{tabular}{|c|c|c|}
\hline Número & Ubicación/ nombre & Cuartel menor \\
\hline 1 & Rivera de San Cosme & 24 \\
\hline 2 & La Tlaxpana & 24 \\
\hline 3 & Buenavista & 24 \\
\hline 4 & Fuente de Soto & 24 \\
\hline 5 & La Alameda & 24 \\
\hline 6 & Corpus Christi & 21 \\
\hline 7 & Puente de San Francisco & 21 \\
\hline 8 & Puente de la Mariscala & 21 \\
\hline 9 & Calle de Zuleta & 7 \\
\hline 10 & Plazuela de Vizcaínas & 7 \\
\hline 11 & Plazuela de Regina & 5 \\
\hline 12 & Colegio de Niñas & 5 \\
\hline 13 & Plaza Mayor & 9 \\
\hline 14 & Salto del Agua & 32 \\
\hline 15 & Santa Bárbara & 28 \\
\hline 16 & Plaza de Santiago Tlatelolco & 28 \\
\hline 17 & Plazuela de San Sebastián & 14 \\
\hline 18 & Plazuela de la Santísima & 25 \\
\hline 19 & Plazuela de Mixcalco & 25 \\
\hline 20 & Parroquia de Santa Cruz & 17 \\
\hline 21 & Puente de Fierro & 17 \\
\hline 22 & Puente del Blanquillo & 17 \\
\hline 23 & Don Toribio & 6 \\
\hline 24 & Plazuela San Salvador & 6 \\
\hline 25 & Revilla Gigedo & 29 \\
\hline 26 & Arcos de Belén & 31 \\
\hline 27 & San Juan & 29 \\
\hline 28 & Plazuela de Santa María La Redonda & 22 \\
\hline 29 & Plazuela de Nuestra Señora de Los Ángeles & 22 \\
\hline 30 & La Lagunilla & 4 \\
\hline 31 & El Factor & 1 \\
\hline
\end{tabular}

Domingo, a la cual debía colocar un remache de bronce en forma de águila. ${ }^{37}$

37 AHCM, AAFP, vol. 58, exp. 32, f. 14. Esta fuente fue descrita por Antonio García Cubas de la siguiente manera; “otra de las típicas fuentes de la capital, 
Para este trabajo es muy importante identificar las fuentes públicas, porque de ellas dependió gran parte de la población. ${ }^{38}$ En el cuadro 3 se presentan las consignadas en 1818.

\section{Plano 3}

FUENTES PÚBLICAS DE LA CIUDAD DE MÉXICO, 181839

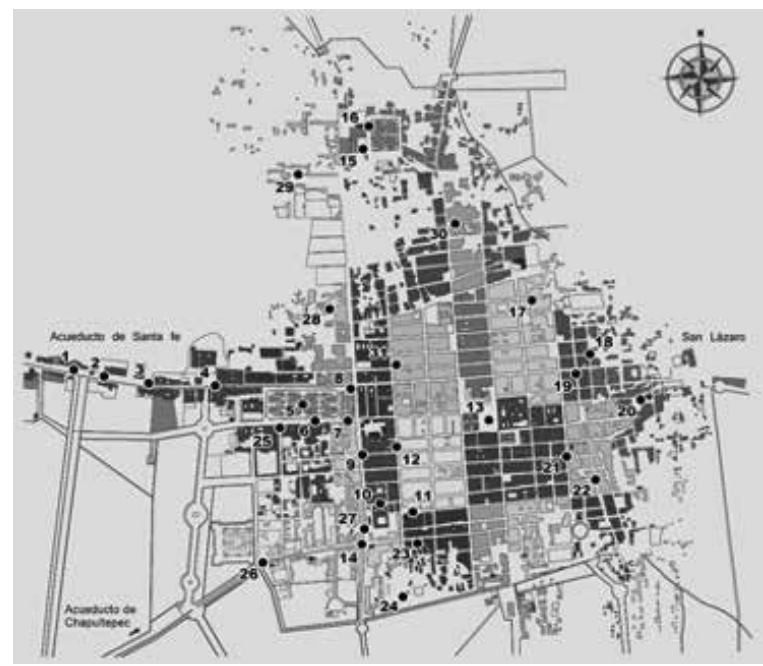

Fuente: elaboración propia con base en el plano de García Conde de 1793 y la visita de 1818.

propia de las construcciones antiguas, era la que se levantaba en la Plaza de Santo Domingo, frente al portal del mismo nombre. Era de forma circular con un tosco pilón en el centro que vertía el agua por cuatro canalillas y se hallaba coronado por una águila parada en un nopal, en actitud de emprender el vuelo”. García Cubas, El libro de mis recuerdos, p. 212.

38 En el cuadro 3 se presentan las fuentes que se consignaron en la visita de 1818. Cabe mencionar que a la del Factor - construida en 1793- hay referencias en diversos documentos. AGN, OP, vol. 1, f. 1164. No se sabe por qué no fue incluida en la relación de 1818. El número de estas fuentes varía en diversos documentos. Por ejemplo, Viera, Breve y compendiosa, p. 152, menciona que había 38 fuentes públicas, pero no menciona cuáles eran, por lo que no se pudo hacer una comparación adecuada.

39 Los números corresponden a los que tienen las fuentes públicas del cuadro 3. 
Después de presentar la ubicación de las diversas zonas, mostraremos un análisis de la sociabilidad del agua en cada una de ellas, ${ }^{40}$ lo que permitirá ver qué función tuvieron las fuentes públicas en la vida cotidiana de la ciudad.

\section{AGUA QUE SOBRA. LAS ZONAS DE PRIVILEGIO}

Gracias al factor población/fuente podemos identificar las zonas con abundancia de agua. En primer lugar, se encontraba la entrada del acueducto de Santa Fe, en el poniente de la ciudad, zona que fue considerada como una de las zonas más favorecidas. Su tierra fértil fue aprovechada para sembrar diversas variedades de árboles y plantas europeas y americanas. Por ello ahí se ubicaron grandes huertas, como la denominada Casa del Cebollón, la de los Once Mil Árboles y la Hacienda de la Teja. ${ }^{41}$

En esta zona se ubicaban las fuentes públicas de la Tlaxpana, la de San Cosme, la de Buenavista y la de Soto (a un lado de San Hipólito), en las cuales con frecuencia se denunciaban derrames. Dentro de los cuarteles considerados dentro de la zona de abundancia de agua, el 24 fue el que tuvo más bajo número de personas por fuente, debido a que contaba con un buen número de públicas y privadas, y una población escasa respecto a otras zonas de la ciudad. Este cuartel tenía agua delgada y también agua gorda. Cabe recordar que el acueducto de Santa Fe contaba con una parte alta que conducía el agua delgada proveniente de ese pueblo y del Desierto de los Leones. En la parte baja del acueducto corría el caudal que derivaba del Río Hondo, desde la taza repartidora ubicada cerca del molino del mismo nombre, en el actual municipio de Naucalpan de Juárez,

${ }^{40}$ La zona de la que menos se hablará es la de carencia absoluta de agua, pues al no generar problemas en la distribución, dejaron menos información que las zonas anteriores. Sus referencias siempre fueron la demanda de extender los caños subterráneos hacia esos lugares.

${ }^{41}$ Reyna y Krammer, Casas y buertas, p. 10. 
y se incorporaba al Río de los Morales y de ahí al Molino del Rey. ${ }^{42} \mathrm{El}$ acueducto bajo llevaba un caudal muy grande, de tal manera que se agolpaba en su paso por la zona poniente. El acueducto pasaba por la Avenida de la Verónica (hoy Melchor Ocampo ${ }^{43}$ y de ahí se repartía a las propiedades ubicadas en sus inmediaciones. En 1804 se observó que la fuerza con la que llegaba el agua gorda ponía en peligro la arquería que conducía el agua de Santa $\mathrm{Fe}$, además de causar inundaciones en la zona. ${ }^{44}$

Los dos tipos de agua fueron ocupados por las huertas aledañas al acueducto. Aunque contaron con mercedes de agua, sus propietarios solían incurrir en el robo del agua del acueducto bajo. Éste fue el caso de las huertas de la Casa Blanca y de la del señor Luyardo, en la Rivera de San Cosme, que en 1801 fueron acusadas del robo del agua del acueducto de Santa Fe. ${ }^{45}$

El agua delgada del acueducto de Sana Fe también era muy abundante, razón por la cual el ayuntamiento otorgó varias mercedes para aprovechar los derrames cerca del convento de San Cosme. Éste fue el caso de una casa inmediata al mencionado convento, que además de gozar de una merced de agua desde 1620 , podía hacer uso del derrame del agua del acueducto alto de Santa Fe que llegaba a la fuente pública de San Cosme. ${ }^{46}$

Las fuentes públicas de esta zona tenían caudales muy grandes. Una de las más famosas era la de la Tlaxpana, construida en el siglo xvi y restaurada en $1737 .{ }^{47}$ Esta fuente, junto con las de Soto, la Rivera de San Cosme y la de Buenavista, contaban con bastante agua: según la vista de ojos realizada en 1792, se calculó

${ }^{42}$ AHCM, $A A D R$, vol. 29, exp. 15, f. 42.

${ }^{43}$ El segundo Conde de Revillagigedo afirmaba que el Paseo de la Verónica era uno de los más importantes porque por ahí pasaba la arquería de Santa $\mathrm{Fe}$, y que lo había recompuesto sólidamente para cuidarlo de las perjudiciales avenidas del Río de los Morales. Revillagigedo, Instrucción reservada, p. 82.

${ }_{44}$ AHCM, $A A R A$, vol. 3876, exp. 266, f. 29.

45 AHCM, $A A F P$, vol. 58, exp. 49, f. 15v.

46 AHCM, $A A D R$, vol. 29, exp. 25, f. 22.

47 Pineda, Origen, p. 218. 
que cada una tenía 18 pajas de agua ( 0.135 litros por segundo, o sea, 2.43 litros por segundo). ${ }^{48}$

Otra de las más importantes fuentes públicas de esta zona fue la de la Mariscala, ubicada a espaldas del actual Palacio de Bellas Artes. Como se ha dicho, de ahí partían los conductos subterráneos que distribuían el agua al resto de la ciudad. A pesar de ser la caja de distribución más importante de la ciudad, era frecuente que quedara seca, sobre todo durante los meses de estiaje. Así sucedió en la Semana Santa de 1796, cuando se observaron constantes variaciones del caudal en un mismo día. ${ }^{49}$ Esta situación repercutía directamente sobre los cuatro ramos subterráneos que de ahí salían, y, por ende, en las fuentes públicas y privadas que se conectaban a esos ramos. Ése fue el caso de 1795, cuando el juez de Aguas, don Cosme Mier y Trespalacios, investigó la causa de la falta de agua en la fuente de Santa Ana (ubicada probablemente en la plaza del mismo nombre, en las inmediaciones de Tlatelolco), y llegó a la conclusión de que era causado por la insuficiencia de caudal que había en la caja repartidora de la Mariscala. ${ }^{50}$ La falta de agua en ese lugar tenía muchas causas, entre ellas el uso abusivo que hacían del caudal las haciendas y molinos ubicados a lo largo del acueducto, así como por ser tiempo de secas, hecho que ocasionaba anualmente la disminución del agua conducida. ${ }^{51}$

A pesar de que había variaciones del agua que llegaba por el acueducto de Santa Fe, las autoridades estaban conscientes de que los usuarios de la entrada eran más beneficiados que

48 AHCM, AAFP, vol. 58, exp. 27, f. 2.

49 Se decía que el Jueves Santo había aumentado su caudal hasta rebosar, pero el Sábado Santo había bajado un tercio de su capacidad, lo que implicaba variaciones muy grandes en el agua que iba a los otros cuatro ramos. AHCM, $A A D R$, vol. 30, exp. 29, f. 1.

50 AHCM, $A A D R$, vol. 30, exp. 29, f. 54.

51 En 1795 se decía que había roturas en el cauce y dispendio en el riego de las huertas. AHCM, $A A D R$, vol. 30, exp. 29, f. 54. 
aquellos ubicados al final de los ramos de agua. En 1777, el procurador general de la ciudad de México afirmaba: “[...] bebe más una paja de agua bajando del Puente de la Mariscala, v. gr. en el Hospital de terceros o san Andrés, que cuatro reales en San Lázaro, porque en el Hospital entra con fuerza y violencia, y en San Lázaro arrastrada". ${ }^{52}$

Otra de las zonas con abundancia de agua fue la zona centro, ubicada en los cuarteles menores 1, 3, 5, 7, 9 y 13 . Estos cuarteles formaban un cuadrángulo ubicado en el centro de la ciudad. Recibían el agua de tres ramos: los de la Santísima y el de Palacio, que corrían desde la fuente de la Mariscala por cada una de las aceras de la calle de Tacuba hacia el oriente de la ciudad. También pasaba por esa zona el ramo de San Francisco, que salía de la caja de la Mariscala hacia el sur, luego doblaba a la izquierda frente al convento del mismo nombre, y de ahí hasta el convento de San Bernardo. Este cuadrángulo contaba con el mayor número de fuentes privadas, así como con un escaso número de fuentes públicas. Entre ellas destacan las del Colegio de Niñas, la de la Plazuela de Regina y dos en la Plaza Mayor. Esta zona central tenía una población con alto nivel económico y también era la que presentaba la mejor de la distribución de agua. Esto se desprende de las escasas quejas que se presentaron por falta de agua en las fuentes de esta zona.

A pesar de ser la zona con el mayor número de fuentes privadas, es un hecho que no todas las casas contaban con una de ella, por lo que también las fuentes públicas siguieron siendo esenciales para la vida diaria de la población asentada en estos cuarteles. Por ello era muy importante mantenerlas en buen estado. Una de ellas estaba ubicada en la plazuela del Colegio de Niñas (actual calle Bolívar). En 1724 recibía un real de agua

52 AHCM, AASFL, vol. 53, exp. 5, f. 15. 
(equivalente a 1.35 litros por segundo). ${ }^{53}$ Pero el paso de los años mermó su eficiencia y para 1793 la fuente se encontraba en pésimas condiciones. Para solucionar esta situación se planeó edificarla nuevamente en la acera que mira al poniente, adosada al edificio, con lo cual se dejaba libre la plazuela. Esta obra se aprovechó también para mejorar el caño subterráneo sobre la calle del Coliseo ${ }^{54}$ Es casi seguro que de ella hayan obtenido agua gran parte de los vecinos de esta zona central, y que por encontrarse en zona privilegiada, no hayan tenido problemas en pagar los servicios de aguadores.

Por su parte, en la Plaza Mayor existieron fuentes desde el siglo Xvi, de las cuales el vecindario también tomaba para su sustento. Viera calificaba a una de ellas como la "famosa fuente que forma un perfectísimo octavo, cuya circunferencia es de 40 varas". ${ }^{55}$ Es probable que no fuera suficiente para cubrir las necesidades del vecindario, por lo que en 1792 se mandaron construir cuatro fuentes, "así para el abasto de agua para el público, como para el aseo y hermosura del paraje". ${ }^{56}$ Sin embargo, es probable que no se hayan realizado las cuatro, pues en 1801 sólo se hacía referencia a dos fuentes públicas. Una de ellas seguramente es la que Viera denominó "la famosa fuente", pues se encontraba en medio de la plaza y tenía una corpulenta águila de bronce de donde salía el agua. ${ }^{57}$ De acuerdo a Rivera y Cambas, la pila que ahí se encontraba era de tan grandes dimensiones que nadie podía alcanzar, por lo que el público debía tomar de otra que tenía muchos desperdicios y basura. La

${ }^{53}$ AHCM, $A A D R$, vol. 29, exp. 15, f. 2. Un real equivalía a 18 pajas, es decir, a 1.35 litros por segundo. Palerm y Cháirez, "Medidas antiguas de agua", pp. 230-239.

${ }_{54}$ AHCM, AAFP, vol. 58, exp. 32, f. 5. AGN, OP, vol. 1, f. 1180.

55 VIERA, Breve y compendiosa narración, p. 28.

${ }^{56}$ AHCM, AAFP, vol. 58, exp. 28, f. 5-5v. AGN, OP, vol. 36, exp. 15, f. 370. Se dice que se terminaron las cuatro fuentes de la Plaza Mayor en diciembre de 1792.

57 VIERA, Breve y compendiosa narración, p. 28. 
gente solía introducir en ella las jícaras con las que antes había bebido pulque o atole. Asímismo, muchas personas lavaban ropas y animales en esa pila, y por si fuera poco, se vendía en sus inmediaciones toda clase de comida. ${ }^{58} \mathrm{~A}$ pesar de este paisaje desolador, es evidente que los habitantes de las inmediaciones utilizaron ambas fuentes para cubrir sus necesidades durante mucho tiempo.

La zona de abundancia de agua constituyó también un privilegio social dentro de la ciudad. En general sus manzanas estuvieron bien constituidas, con gran población habitando en ella. Si bien en casi todas partes de la ciudad se padecía de escasez cuando llegaba insuficiente caudal a la caja de la Mariscala, es evidente que la mayor parte del tiempo se tenía una mejor distribución, por encontrarse a la entrada de la ciudad. Esta zona fue densamente habitada, lo cual no hubiera sido posible sin un caudal que asegurara la vida diaria de este vecindario. Además del agua delgada, la de menor calidad permitió el riego en las huertas ubicadas en la parte poniente de la ciudad, lo que creó un paisaje muy agradable a la vista. Las fuentes públicas ubicadas a la entrada de la ciudad no sólo fueron aprovechadas por los vecinos asentados en sus inmediaciones, sino también por otros más que se desplazaban a esas fuentes desde lugares menos favorecidos, como se verá más adelante.

\section{LA ZONA INTERMEDIA O DE CONEXIÓN, ENTRE LA ABUNDANCIA Y LA CARENCIA}

La zona de distribución intermedia estuvo constituida por cuarteles que tenían entre 351 y 1000 personas por fuente. Éstos se encontraban tanto en el sur, a la entrada del acueducto de Chapultepec, como en el norte, en las inmediaciones de Tlatelolco. Llama la atención que en estos cuarteles se

${ }^{58}$ Rivera, México pintoresco, t. 1, p. xxvii. 
ubicaban los barrios de San Juan, en el sur, y de Santiago, en el norte, lo cual indica el interés, por parte de las autoridades, de surtir de agua a la población indígena. No obstante, llama la atención que en la visita de 1818 no hubo ningún indígena que contara con merced particular. Ni siquiera los gobernadores de las parcialidades tuvieron este privilegio. Esto se debió probablemente a que el costo por el servicio era muy alto, como ya se ha mencionado. Pero también nos permite considerar al agua como un factor de diferenciación estamental y social, que sólo se puede apreciar con los datos que arroja la visita de 1818.

Otra parte de la zona de distribución intermedia se ubicaba en el oriente de la ciudad, en un cuadrángulo comprendido por los cuarteles $11,14,17$ y 25 . En estos cuarteles terminaban los ramos de distribución de la Santísima y de San Francisco, de agua delgada, así como los de la Merced y San Pablo, de agua gorda. A pesar de contar con numerosas fuentes públicas y privadas, estos cuarteles presentaron frecuentes problemas para obtener el vital líquido, justo por encontrarse al final de los caños de distribución.

La primera de las zonas de que hablaremos es la ubicada a la entrada del acueducto de Chapultepec. Las fuentes públicas que recibían este caudal estaban entre el Colegio de Belén y el Salto del Agua. Como sucedía con la entrada del agua delgada, en este lugar el agua gorda también venía con gran fuerza por el acueducto, por lo que, al entrar a la ciudad, se derramaba a lo largo de la calzada de Belén y hasta su remate, en la fuente de Salto del Agua. El Ayuntamiento también otorgó mercedes por los derrames del agua, pero el caudal era tan grande, que muchas veces los beneficiados no podían aprovecharla toda y terminaba por derramarse en la vía pública. Éste fue el caso de un vecino de las inmediaciones del acueducto, quien tenía permiso para aprovechar los derrames, pero en enero de 1793 fue acusado de no tener en forma adecuada el conducto, por lo que el líquido 
se fugaba hacia la avenida. ${ }^{59}$ Los derrames continuaron, de tal manera que en diciembre de ese año ya era imposible realizar el empedrado, pues los remanentes del agua se vertían en toda la Calzada de Belén. El arquitecto mayor, don Ignacio Castera, propuso hacer caños de barro subterráneos en cada fuente, para que la conducción de agua fuera profunda y no al ras de tierra. ${ }^{60}$ Esto no se realizó, por lo que en 1795 los problemas en esta calzada seguían siendo un gran inconveniente para los transeúntes.

Además del derrame ocasionado por la fuerza con que entraba el agua del acueducto de Chapultepec, se presentó otro factor que favoreció los encharcamientos. Cabe recordar que durante la década de 1790 se suprimieron varias acequias que atravesaban la ciudad, a fin de evitar zonas infectas o malos olores. Esto ocasionó diversos problemas en la disposición del agua. Lo más grave de este caso es que se tiraba agua que podía haberse utilizado para necesidades humanas. En el barrio de Montserrat, al sur de la ciudad, corría una acequia que pasaba atrás del convento de Regina Coeli, y de ahí se dirigía a las carnicerías, es decir, al barrio de San Pablo. ${ }^{61}$ Cuando las autoridades inspeccionaron la zona llegaron a la conclusión de que los encharcamientos se hacían como consecuencia de haber cegado el tramo de la acequia real que atravesaba el barrio de San Juan. ${ }^{62}$ Esto suena lógico, pues las acequias fueron por siglos el receptáculo del agua pluvial y de desecho, y formaron parte del sistema de desagüe de la ciudad.

Para aprovechar los continuos derrames en esta zona, en 1795 se planeó usar agua gorda para regar la Alameda. Con ello se evitaba usar el agua delgada del acueducto de Santa Fe, que corría al norte de este parque, para la irrigación de ese parque. Esta obra dio lugar a la creación del ramo del Bosque, que fue

59 AHCM, $A A D R$, vol. 30, exp. 30, f. 1.

60 AHCM, AAFP, vol. 58, exp. 35, f. 2.

${ }^{61}$ Cisneros, Sitio, naturaleza y propiedades, p. $110 \mathrm{v}$.

${ }^{62}$ Lombardo, Territorio y demarcación, p. 26. 
denominado así porque corría por el callejón del mismo nombre y atravesaba la antigua parcialidad de San Juan. Este ramo iba también hasta la cárcel de la Acordada, al sur de la Alameda. A lo largo de su trayecto se abrieron nuevas conducciones hacia tomas privadas. ${ }^{63}$ En la calle Ancha, paralela al conducto, también se construyó una nueva fuente pública.

A fines del siglo XviII se llevaron a cabo varias obras en la Alameda, que no sólo ampliaron el jardín, sino que también propiciaron el mejoramiento del riego y llevaron agua a sus numerosos visitantes. Gracias a estas obras de edificó una gran fuente al centro, con 50 varas de circunferencia, finamente adornada con cantería y diversas estatuas. ${ }^{64}$

A pesar de la importancia de este paseo público, en 1801 se reportaba que, con mucha frecuencia, esta fuente carecía de agua, lo cual afectaba tanto a los paseantes como a los vecinos de esa zona. ${ }^{65}$ También en ese mismo año se reportaba una notable disminución de agua en las inmediaciones de los Arcos de Belén, así como la falta total en la fuente de Salto del Agua. Era frecuente que el agua de Chapultepec fuera extraída indebidamente con el uso de bombas a lo largo de su curso. ${ }^{66}$ Con este fenómeno se vieron afectados propios y extraños de esta zona sur de la ciudad.

En el cuartel 29 se ubicaban dos importantes fuentes públicas: la de Revillagigedo y la ubicada en la plazuela de San Juan. Llama la atención que durante el periodo estudiado no se encuentran quejas por la falta de agua en ninguna de estas dos fuentes. Sin embargo, es probable que sí existieran periodos de disminución en el caudal, debido a que esto mismo se reportó en fuentes cercanas.

\footnotetext{
63 AHCM, $A A D R$, vol. 30, exp. 29, f. 43.

64 Viera, Breve y compendiosa narración, p. 102.

65 AHCM, $A A F P$, vol. 58, exp. 49, f. 3.

66 AHCM, $A A D R$, vol. 30, exp. 19, f. 42.
} 
Otro cuadrángulo dentro de la zona intermedia era el que formaban los cuarteles $11,14,17$ y 25 , ubicados en la zona centro oriental de la ciudad. Una de las fuentes más importantes para este vecindario era la fuente de San Sebastián, ubicada en el cuartel $14,{ }^{67}$ que fue construida en 1703 para favorecer a una numerosa población. Éste era uno de los cuarteles más habitados, con 11018 personas en 1816. Tan sólo contaba con 24 fuentes privadas y una pública. Es por ello que la de San Sebastián fue una de las fuentes más visitadas, y también de la cual se recibían más quejas, por estar al final de los ramos. En 1786, el virrey Conde de Gálvez afirmaba que la escasez experimentada en esos tiempos afectaba más "a los habitantes que viven en las calles más apartadas del centro, y los que tienen vecindad en los suburbios $[\ldots]{ }^{\prime} .68$

A finales del siglo xviII se aseguraba que la pila pública de San Sebastián favorecería la llegada de nuevos vecinos a la zona, además de evitar los tan mencionados "pecados públicos”. Para ese cometido, se aprovechó el caño de agua que llegaba a esa parroquia y que de ahí pasaba hacia el convento del Carmen. ${ }^{69}$ Este conducto se deterioró paulatinamente, hasta que alrededor de 1770 esta fuente dejó de tener uso por carecer por completo de agua. En 1796 se pidió su reconexión, pero su alto costo hacía muy difícil que se llevara a cabo. ${ }^{70} \mathrm{La}$ situación era tan desesperada en 1799 que los alcaldes y regidores indios de esta parte de la ciudad realizaron una petición formal al Ayuntamiento para arreglar el caño subterráneo y restituir el agua corriente. ${ }^{71}$ Pero

${ }^{67}$ En la visita de 1818 esta fuente estaba contada dentro del cuartel menor 25. Pero de acuerdo al plano de García Conde de 1811, la plaza de San Sebastián se ubicaba en el cuartel menor 14, por lo que para este estudio se decidió contabilizarla dentro de esta demarcación.

68 AHCM, $A A F P$, vol. 58, exp. 49, f. 2v.

${ }^{69}$ AHCM, $A A F P$, vol. 58 , exp. 3 , f. 6.

70 AHCM, $A A F P$, vol. 58, exp. 44, f. 2.

71 AHCM, AAFP, vol. 58, exp. 46, f. 1-2. 
tal parece que hicieron caso omiso a este documento, pues en 1800 se informó al virrey la falta total de agua en esta pila y la gran necesidad de ponerle remedio a la situación. ${ }^{72}$

Dentro de esta zona también se ubicaban las fuentes públicas del Carmen, San Sebastián, Santo Domingo, la Santísima y Mixcalco. ${ }^{73}$ Las quejas por falta de caudal fueron una constante desde el último cuarto del siglo xviII. Los vecinos debían movilizarse de una a otra fuente para surtirse de agua, tal como se observa en una queja levantada en 1786 . Se decía que los vecinos de Nuestra Señora de Loreto, Santa Teresa la Nueva, Santísima Trinidad y sus contornos denunciaban la "gravísima falta del agua de las pilas públicas que hasta la exasperan y claman los pobres, a más de la consternación de la presente enfermedad y escasez de mantención tan pública [...]”. ${ }^{74}$

Igual situación vivían las casas cercanas al convento del Carmen y a la fuente pública ubicada en esa plazuela, que con frecuencia presentaba variaciones en su caudal. Por si fuera poco, la construcción del Cuartel de Artilleros en la calle de Arcinas mermó aún más la dotación de esta zona. En 1792 se decía que el caño subterráneo no era suficiente para surtir la fuente de San Sebastián, por lo que ambos lugares padecían escasez. ${ }^{75}$ En vista de la necesidad que vivían los vecinos, el convento del Carmen permitió que el público en general entrara a tomar agua de su fuente interior, a pesar de que llegaba con muy poca fuerza, o como decían entonces, muy arrastrada, por lo que no se llenaban las pilas de la zona. En 1803 se vivieron días enteros de carestía de agua en esa zona, dependiendo de las pocas sobras que tenía el convento. ${ }^{76}$ La situación en este barrio no mejoró con el paso

\footnotetext{
72 AHCM, AAFP, vol. 58, exp. 46, f. 7.

73 Como se ha dicho, la fuente de la Plaza del Factor no se mencionó en la visita de 1818, por lo que se omite en este listado.

${ }^{74}$ AHCM, $A A D R$, vol. 29, exp. 22, f. 3-3v.

75 AHCM, $A A F P$, vol. 58, exp. 29, f. 5.

${ }^{76}$ AHCM, $A P$, vol. 3629, exp. 135, f. 3.
} 
de los años, pues todavía en 1815 se decía que el vecindario tomaba agua del convento, pero esto era limitado, pues solamente podían entrar hombres. Las mujeres solían ser las más afectadas, pues debían recorrer mayores distancias para obtener el vital líquido que demandaban sus familias. ${ }^{77}$

En esta zona también se encontraba la fuente de la Santísima, que recibía el agua que debía llegar hasta San Lázaro, de tal manera que si algo afectaba a la primera, el hospital no recibía ningún caudal. En 1800, dado que el Hospital de San Lázaro no contaba con agua suficiente para la atención de sus enfermos, se propuso quitar agua a la fuente de la Santísima por varias horas ciertos días. ${ }^{78}$ Pero esta tampoco fue una solución, pues a la fuente de la Santísima llegaban tan sólo unas gotas al día.

El problema con estas fuentes no sólo provenía de su ubicación al final de los caños subterráneos del agua. Algunas veces los cobros abusivos que hacían algunas personas encargadas del cuidado de los conductos provocaban la escasez. Así sucedió en 1796 en la fuente de la Santísima, lo que motivó una profunda investigación entre los cañeros y sobrestantes de la conducción del agua. En este caso, quienes los acusaron fueron diversos aguadores que debían pagar hasta medio real diario al sobrestante de esa fuente para que soltara el agua. Sin embargo, cuando éstos y el administrador del baño de Los Clérigos se negaron a las exigencias monetarias de estos personajes, estos últimos procedieron a cerrar la salida del agua de esta fuente con trapos. El propio conducto subterráneo fue clausurado con zulaque, lo que afectó no sólo a la fuente de la Santísima, sino a la posterior, que era la de la Santa Cruz. ${ }^{79}$

\footnotetext{
77 AHCM, $A A F P$, vol. 58, exp. 34, f. 5.

78 AHCM, $A A D R$, vol. 30, exp. 29, f. 22.

79 AHCM, $A A F P$, vol. 58, exp. 47, fs. 1-9v. Gracias a las declaraciones de los aguadores, se pudo encontrar al culpable, un cañero apodado "El Chavacano" [sic], quien fue condenado a la cárcel pública.
} 
Podemos suponer que los habitantes cercanos a la fuente de la Santísima recurrieron al agua de la que estaba ubicada en la plazuela de Santa Cruz y la Soledad. Es difícil decir cuál era la calidad del agua de esa fuente. El párroco de la Palma afirmaba que esa pila siempre contaba con agua limpia, ${ }^{80}$ pero otra versión la tenía el cura de Santa Cruz, al afirmar que eran pocos los días enteros que contaba con el vital líquido. ${ }^{81}$

Una de las zonas que recibió agua desde el siglo xvi fue la de las inmediaciones del convento de Santo Domingo, que comenzó a poblarse profusamente a partir de la llegada de esa orden religiosa al lugar. Sin embargo, con el tiempo la fuente pública ubicada en esa plazuela se deterioró, de tal manera que fue necesaria su reconstrucción en 1793, el mismo año en que otras fuentes fueron arregladas o construidas. Pero en este caso, además de la fuente, era necesario rehacer el caño subterráneo, lo cual no se pudo concluir como se había planeado, por lo que esta fuente quedó sin funcionar por algunos meses..$^{82}$ En septiembre de ese año, la pila estaba terminada, restando la colocación del águila de bronce en el remate. ${ }^{83} \mathrm{Tal}$ parece que la fuente comenzó a funcionar unos días después, aunque cabe decir que no fue incluida en la visita de 1818.

Otro cuartel menor ubicado dentro de la zona intermedia fue el 28, que corresponde a parte de la parcialidad de Santiago Tlatelolco. Como se observa en el plano de García Conde, las manzanas tenían allí una disposición mucho más dispersa que en los cuarteles centrales. Sus habitantes se dedicaron a actividades agrícolas, sus calles estaban mal trazadas y todavía en el siglo XviII sus familias prestaban servicios a las tierras de la comunidad. ${ }^{84}$

\footnotetext{
80 AHCM, $A A F P$, vol. 58, exp. 41, f. 5v.

81 AHCM, $A A F P$, vol. 58, exp. 7, f. 28.

82 AHCM, $A A F P$, vol. 58, exp. 30, f. 2.

83 AHCM, $A A F P$, vol. 58, exp. 32, f. 14.

84 Gonzalbo, Del barrio a la capital, p. 58.
} 
El agua que recibía este barrio era delgada y venía en un conducto desde el ramo de San Lorenzo, que derivaba de la caja de la Mariscala. Cabe resaltar que si bien los indios no tuvieron mercedes de agua privada, sí tuvieron la administración directa de algunas fuentes públicas. Éstas eran las de San Martín (que se pasó luego a la parroquia de Nuestra Señora de los Ángeles), la de Guadalupe y la de la Plaza Mayor de Santiago. ${ }^{85}$ Esta agua también era aprovechada por otras fuentes públicas que corrían hacia el oriente. Una de ellas estaba en la parroquia de Santa María, dentro del recinto parroquial, y otra más en la plazuela. De esta última se beneficiaban los vecinos de los barrios circunvecinos, los cuales vivían muy dispersos. Rivera y Cambas afirmaba que ese barrio estaba habitado por "una gran masa de pueblo que vegetaba en pocilgas", ${ }^{86}$ haciendo referencia a la pobreza de la zona.

Hacia el oriente existía otra fuente, denominada de La Habana, cerca del Puente de las Guerras, a donde acudían los vecinos de la zona cuando la de Santa María se encontraba seca. Pero la segunda fuente era de menor capacidad, por lo que no alcanzaba a cubrir las necesidades de esa población. De acuerdo a una vista de ojos realizada en 1772, recibían muy poca agua porque parte del caudal era utilizado por la Real Fábrica de Puros y Cigarros. ${ }^{87}$ Tres años después se observó que tampoco la fábrica tenía agua suficiente y en igual condición se encontraban los vecinos de Tlatelolco, por lo que no hubo manera de mejorar la situación para los habitantes de esa zona. ${ }^{88}$ Para poner solución al estado de la parroquia de Santa María, su párroco no se conformó con hacer las denuncias pertinentes, sino que dejó

\footnotetext{
${ }^{85}$ AHCM, $A A F P$, vol. 58, exp. 25, f.16. La fuente de San Martín a la que se hace referencia no aparece en la lista de 1818.

${ }^{86}$ Rivera, México pintoresco, t. 2, p. 65.

87 AHCM, $A A F P$, vol. 58, exp. 13, f. 2.

${ }_{88}$ AHCM, AAFP, vol. 58, exp. 13, f. 15v.
} 
la cantidad de 9000 pesos para una obra pía que consistió en mantener y conservar la fuente de ese lugar. ${ }^{89}$

En 1790 se hizo una nueva medición, en la que se determinó que toda la zona norte, con sus siete fuentes, recibiría una naranja de agua, equivalente a 144 pajas de agua (1.08 litros por segundo). En este reparto se observan las grandes diferencias en la capacidad de estas fuentes, razón por la cual algunos vecindarios gozaron de más agua que otros. Entre todas ellas, la de Santa María, la de Guadalupe y la de San Martín eran las de menor capacidad, pues tan sólo recibirían 9 pajas (0.337 litros por segundo); las de La Lagunilla y la del Colegio de San Buenaventura, 36 pajas ( 0.27 litros por segundo), y la más grande, era la de la Plaza Mayor de Santiago Tlatelolco, 45 pajas ( 0.337 litros por segundo). ${ }^{90}$ Pero como sucedía con otras mercedes de agua, el hecho de que se les concedieran dichos caudales no significaba que efectivamente llegaran a la pila. La razón era que todas estas fuentes se encontraban al final del ramo subterráneo y el caudal del que gozaban venía muy mermado por el uso que se hacía del agua antes de su llegada a ese punto. Así que el reparto de la naranja de agua no solucionó el problema. Por ejemplo, en 1808 se decía que la fuente de La Lagunilla tenía muy poca agua por encontrarse al final del ramo que venía de Tlatelolco, así como porque los cuarteles de caballería ubicados antes de ella consumían grandes cantidades de agua. ${ }^{91}$

En 1795 los habitantes de Santiago Tlatelolco volvieron a padecer de escasez en sus fuentes, y de acuerdo a un escrito presentado por el escribano del Juzgado de Naturales, era la causa

\footnotetext{
89 AHCM, AADR, vol. 30, exp. 29, f. 65.

90 La fuente de Guadalupe no está considerada en el plano porque no es mencionada en ningún informe cercano a 1818. La de San Martín, como se recordará, se pasó a la plazuela de la parroquia de Nuestra Señora de los Ángeles. AHCM, $A A F P$, vol. 58, exp. 25, f. 16.

91 AHCM, $A P$, vol. 3626, exp. 157, f. 50.
} 
de que el vecindario fuera disminuyendo. ${ }^{92}$ En mayo de ese año se decía que la fuente de La Lagunilla, también llamada de Santa Ana, no llegaba una gota de agua. El problema no era sólo en ese lugar, sino que incluso la caja repartidora de la Mariscala padecía de escasez en el mes de junio, lo cual evidentemente afectaba a los ramos que dependían de este depósito. ${ }^{93}$ Las autoridades de la ciudad hicieron una investigación para poner remedio a la falta de agua en las fuentes públicas. Encontraron varias causas, entre ellas las omisiones de los sobrestantes (cuidadores) de las fuentes. También se señaló haber ubicado un tanque y un lavadero detrás del "tecpan” de Santiago Tlatelolco que hacían disminuir el caudal. Y por último se decía que en el Colegio de San Buenaventura había mucho desperdicio del líquido, ya que recientemente se había abierto una toma en el cementerio anexo, aprovechando el paso de un ramo subterráneo, y que en ocasiones se dejaba abierta la toma, lo que calificaron como un "descuido nocturno". ${ }^{94}$ Es un hecho que los habitantes de esta zona siguieron sufriendo de escasez de agua, razón por la cual el vecindario no creció durante muchas décadas del siglo XIX, así como tampoco se compactaron sus manzanas.

En el sureste de la ciudad se encontraban los cuarteles 11 y 17, que también fueron parte de la zona intermedia. Ahí se localizaba el barrio de San Pablo, conocido también con el nombre de los Curtidores, pues estos artesanos, así como los zapateros, zurradores y badaneros, ${ }^{95}$ aprovechaban el paso de la acequia real para verter sus desperdicios. Desde el siglo xvi se había edificado en ese barrio una fuente pública que con el tiempo y

\footnotetext{
92 AHCM, $A A D R$, vol. 30, exp. 29, f. 63.

93 AHCM, $A A D R$, vol. 30, exp. 29, f. 49.

94 AHCM, $A A D R$, vol. 30, exp. 29, fs. 39 y 68.

${ }^{95}$ Zurrador era la persona que ejercía el oficio de zurrar, que era curtir los cueros. Diccionario de autoridades. El badanero era una persona que se dedicaba a comercializar badanas, es decir, pieles curtidas y finas de carnero u oveja.
} 
el uso se fue deteriorando. En 1738 se arregló esta pila, gracias a la conexión de un ramo subterráneo que iba desde el Salto del Agua. ${ }^{96}$ Pero en 1762 había frecuentes quejas de la falta total de agua en esta fuente, lo cual afectaba al numeroso vecindario que ahí residía. Uno de los vecinos de ese barrio se quejó ante las autoridades por las grandes distancias que los pobres debían recorrer para cubrir sus necesidades, y para ello debían enviar a "sus hijos y a sus hijas por ella [lo que] los expone a muchos riesgos". ${ }^{97}$ Este argumento fue muy usado por los habitantes, que exigieron al Ayuntamiento soluciones inmediatas a la falta de agua.

En 1795 el problema se complicó, ya que era muy común que el buque por donde salía el agua estuviera totalmente tapado. En principio se pensó que el azolve se debía a que los aguadores se metían a la pila para llenar sus cántaros, ${ }^{98}$ pero esta teoría fue desechada cuando las autoridades hicieron una vista de ojos y se percataron de la presencia permanente de gusanos "dimanando de las inmundicias que en sus inmediaciones se arrojan”. Tras varias limpiezas que se hicieron en su buque y pila, se decidió levantar por completo la fuente. La sorpresa no se hizo esperar al observar que infinidad de gusanos blancos y colorados tenían su criadero adentro y debajo de la construcción, por lo que la fuente se clausuró completamente. ${ }^{99}$ Ante tal situación, las autoridades dieron la orden de que el Colegio de San Pablo, así como un particular que vivía en el callejón de San Camilo, permitieran a las personas tomar el vital líquido de sus fuentes. Sin embargo, y como sucedía en el convento del Carmen, a dicho colegio sólo podían acceder los varones, por lo que las mujeres tenían que recurrir al baño que se encontraba en la misma plazuela de San Pablo. De inmediato se planeó y proyectó una

\footnotetext{
96 Gaceta de México, vol. 3, pp. 87-88.

97 AHCM, $A A F P$, vol. 58, exp. 11, f. 1.

98 AHCM, $A A D R$, vol. 30, exp. 29, fs. $35-35 \mathrm{v}$.

99 AHCM, $A A F P$, vol. 58, exp. 42, fs. 1-3.
} 
nueva fuente pública en las cercanías de la plazuela, en las calles de la Garrapata y de la Buena Muerte, pero la obra no se llevó a cabo. ${ }^{100}$ En esas circunstancias tan apremiantes, los habitantes de esa zona debían recurrir a otros medios para hacerse del agua. Por ejemplo, aprovechaban la que se derramaba por los viejos caños que conducían el agua hacia la plazuela de San Pablo. ${ }^{101}$

La fuente de San Pablo quedó fuera de servicio por muchos años, lo cual tuvo graves consecuencias no sólo para los habitantes de este barrio sino también para los cuarteles aledaños que no contaban con fuentes en su demarcación.

Como se ha podido observar, la zona intermedia contaba con fuentes públicas y privadas, pero con una distribución muy deficiente de agua. El hecho de encontrarse al final de los caños subterráneos, así como la falta de fuerza por el sistema de gravedad, ocasionó que las fuentes tuvieran un suministro muy deficiente. No obstante, al encontrarse contigua a la zona de abundancia, sus habitantes pudieron acarrear agua de lugares más beneficiados. Aunque tuvieran poca agua, era evidente que tenían mejores condiciones que las otras dos zonas de la ciudad, y esto es notorio por la cantidad de habitantes con las que contaron. La ocupación de espacio en los cuarteles centro orientales y del sur oriente fue muy compacta, por lo que podemos suponer que en ello fue determinante que hubiera conductos de agua por esa zona. Incluso en Tlatelolco, que siempre sufrió de escasez de agua, las fuentes que derivaban del caño que surtía la plaza principal de esta parcialidad permitieron que la población continuara ocupando esta zona por siglos. Era un hecho que tuvieron más posibilidades de vida en esta zona, que por encontrarse contigua a áreas con mejor distribución de agua y tener más posibilidades económicas, pudieron utilizar el servicio de los aguadores para surtirse del vital líquido en tiempos de escasez.

100 AHCM, $A A F P$, vol. 58, exp. 42, f. 13.

101 AHCM, $A A D R$, vol. 30, exp. 29, f. 46. 
AGUA QUE FALTA. LAS ZONAS DE ESCASEZ Y CARENCIA TOTAL

Las situaciones más apremiantes de la ciudad se vivieron en las zonas que hemos denominado de escasez y carencia total de agua. Los cuarteles considerados en este rubro tenían menos de 5 fuentes en total y más de 1000 personas por fuente. Se ubicaban en las zonas marginales de la ciudad, en donde la ocupación del espacio fue dispersa, y por mucho tiempo no lograron consolidar sus manzanas. La zona de escasez tuvo casi igual número de fuentes públicas que de privadas, lo cual nos permite deducir que había un caudal limitado, y que sus pobladores tenían escasos recursos económicos. Como se dijo anteriormente, el agua también fue un elemento de división estamental en la ciudad, y los cuarteles que tenían pobreza hídrica también fueron los de mayor marginación social. La población de estos cuarteles obtenía el agua de las fuentes públicas ubicadas en las áreas contiguas de la que hemos denominado zona intermedia, e incluso en zonas de abundancia. Por ello, cuando el agua faltaba en la zona intermedia, no sólo eran afectados estos cuarteles, sino también los de la zona de carencia.

En la parte norte podemos ubicar varias fuentes públicas. Dentro del cuartel 22 estaban las de las plazuelas de Santa María, ubicada en la parroquia del mismo nombre, y la de Espíritu Santo, a espaldas de esa iglesia. A estas fuentes acudía el vecindario que habitaba cerca de los puentes del Clérigo (ubicado en el cuartel 4, en las inmediaciones de la acequia de Tezontlale) y de las Guerras, hasta el barrio de Tepichichilco. ${ }^{102}$ Toda esta zona presentaba una ocupación de espacio muy dispersa, la cual disminuyó aún más a finales del siglo xviII, debido a que el agua no llegaba por ser muy pequeño su conducto. En 1772 se observó que el agua se desperdiciaba por la noche, por lo que en la mañana estaba totalmente seca. Quien abogó por el mejoramiento

102 AHCM, AAFP, vol. 58, exp. 13, f. 2. 
de esta fuente fue su párroco, que calculaba en 8000 las personas que aprovechaban este caudal.

Cerca de la acequia de Tezontlale se encontraba la fuente de La Habana, que en 1772 tenía una muy pequeña pila y muy poca agua. ${ }^{103}$ Esta fuente, así como la de Santa María y la del Espíritu Santo, sufrieron la disminución de su caudal como consecuencia de la naranja de agua que había recibido Santiago Tlatelolco en la década de 1770. También les había afectado el agua que recibían las cuatro fuentes de la Real Fábrica de Puros y Cigarros. En 1790 ya no era mencionada la fuente de La Habana, por lo que podemos suponer que se suprimió en ese lapso. La situación no mejoró en el barrio de Santa María, pues en 1786 los curas se quejaban de nuevo por la falta de abasto de agua en la fuente del patio interior. ${ }^{104}$ Fue en 1809 cuando se aceptó otorgar los derrames de la fuente de la plazuela a la parroquia de Santa María. No obstante, el agua fue insuficiente para solventar las necesidades de la población, pues las autoridades prefirieron conducir agua a la plaza de Tlatelolco que a esta zona. Es probable que los habitantes del barrio de Santa María acudieran a tomar agua de las fuentes públicas ubicadas sobre el acueducto de Santa Fe, dada la relativa cercanía con esta zona.

Por la parte oriente de la ciudad también se vivía una situación de total carencia. La última fuente del ramo de la Santísima era la de San Lázaro, que llegaba al hospital del mismo nombre. En el cuartel 26 sólo existían ésta y otras dos tomas particulares. Es por ello que su población debía acudir a la fuente de San Sebastián para cubrir sus necesidades. Las quejas de las personas que debían ir a ella desde lugares alejados nos muestran los peligros a los que podían enfrentarse en este trayecto. En 1799 se decía que los pobres debían enviar a sus mujeres e hijas a fuentes lejanas, exponiéndolas a riegos tan graves como "el desfloramiento

103 AHCM, $A A F P$, vol. 58, exp. 13, f. 5.

104 AHCM, $A C, 14$ de agosto de 1786. 
de hijas, o que algún hijo saliera jugador u otros inconvenientes morales" ${ }^{105}$ Como ya se ha mencionado, si el agua faltaba en la fuente de San Sebastián, los habitantes de la zona oriental también resultaban muy afectados.

$\mathrm{Al}$ sureste de la ciudad se encontraba una de las zonas con mayores problemas. Los cuarteles 18,19 y 20 no contaron con ninguna fuente, por lo que se vieron obligados a acudir a otras zonas para obtener el vital líquido. La ocupación del espacio en estos cuarteles fue irregular. Ahí se ubicaban los barrios de La Palma, la zona aledaña al Paseo de Revillagigedo (La Viga) y Xamaica. En 1793 se construyó la fuente del Puente de Fierro, ${ }^{106}$ por lo que los barrios cercanos de San Pablo, La Palma, el Hornillo y Xamaica tomaban agua de esta pila, así como de la de San Pablo. Pero cuando se retiró esta última, los habitantes de esta amplia zona vieron limitadas sus posibilidades de hacerse de agua limpia. De acuerdo al cura de la parroquia de La Palma, las familias que no podían ir personalmente por el agua, debían gastar hasta medio real por dos o tres viajes de los aguadores. Y por si fuera poco, debían esperar mucho tiempo hasta que la multitud surtieran sus cántaros. ${ }^{107}$

El agua gorda, que en esos tiempos era calificada como de mala calidad, hubiera sido oro puro para los habitantes de esa zona. Por ello el cura de La Palma pedía que se estableciera una fuente al final del ramo de La Merced, para beneficio de sus feligreses. Entre sus argumentos se ponderaba la necesidad que se vivía para cubrir los usos domésticos, pero también urgía para atender con dignidad las ceremonias religiosas. Para favorecer esta obra, los vecinos de la parroquia ofrecieron ayudar monetariamente al Ayuntamiento con una cuarta parte del costo de la obra. Se decía que hasta antes de 1794, año de este documento,

\footnotetext{
105 AHCM, $A A F P$, vol. 58, exp. 46, f. 1.

106 AGN, OP, vol. 37, exp. 6, f. 23.

107 AHCM, $A A F P$, vol. 58, exp. 41, fs. 2-3.
} 
ya había habido una pequeña fuente en la esquina del callejón de Tlapala y que por ello era factible poner una en su barrio. ${ }^{108} \mathrm{~A}$ esta causa también se unieron algunos comerciantes avecindados en ese barrio. ${ }^{109}$ Esta propuesta no fue atendida por el Ayuntamiento, en gran parte porque el sistema de gravedad impedía la llegada de agua a lugares más alejados. Así que los pobladores de esta parroquia siguieron acarreando agua tanto de la fuente del Puente de Fierro, como de la del Blanquillo. Todavía en 1815 esta última fuente era ampliamente visitada por los habitantes del sureste de la ciudad. Pero como sucedía con otras fuentes públicas, el agua solía escasear, por lo que el numeroso vecindario que acudía a este lugar debía trasladarse a las fuentes ubicadas varias manzanas al norte, en las plazuelas de la Santísima y la de Loreto. ${ }^{110}$ Esto significaba un desplazamiento muy pesado para los habitantes de la zona sur o, en su defecto, recurrir al servicio de aguadores, que por tener que surtirse en zonas alejadas, cobraban sumas más altas en zonas muy pobres.

Como se pudo observar, las necesidades de agua de los habitantes de las zonas de escasez y de carencia eran muchas y les fue muy difícil cubrirlas por la lejanía de las fuentes públicas, así como por la mala calidad del agua que llegaba a ellas. El hecho de encontrarse al final de los ramos de distribución impedía la llegada de un caudal limpio y constante. El costo humano de trasladarse a zonas alejadas para el acarreo del agua, así como el alto precio del servicio de los aguadores, provocaron que el vecindario de estos cuarteles fuera, en términos generales, muy limitado. El cuartel menor 2 fue el que tuvo el mayor número de habitantes de las zonas de carencia, con 6754 habitantes. Su cercanía con las fuentes públicas ubicadas cerca de la acequia de Tezontlale le permitió contar con esa población. Pero los

${ }^{108}$ La presencia de esta fuente no se ha podido comprobar en los documentos.

109 AHCM, $A A F P$, vol. 58, exp. 41, f. 3.

110 AHCM, $A A F P$, vol. 58, exp. 34, f. 5. 
cuarteles sin ninguna fuente, además de tener una ocupación dispersa del espacio, tuvieron muy poca población. El caso más evidente de ello es el cuartel 27, con tan sólo 735 habitantes en 1816. Estas zonas no crecerían demográficamente sino hasta la introducción de los pozos de agua, a mediados del siglo xIx. ${ }^{111}$ Pero esto forma parte de otro momento que rebasa los límites temporales de este estudio.

\section{CONSIDERACIONES FINALES}

En este trabajo se ha podido documentar que el sistema de distribución de agua en la ciudad de México fue incapaz de surtir a todos sus habitantes. El gran esfuerzo que hacían las autoridades del cabildo por conducir agua desde manantiales lejanos a la ciudad y lograr su distribución posterior por los ramos subterráneos, no logró hacer que el agua llegara a todas las fuentes. La ciudad contaba en 1818 con 329 fuentes públicas y privadas, que eran incapaces de cubrir las necesidades de una población que en 1816 ascendía a 152668 habitantes. El sistema de gravedad en que se basaba el funcionamiento de este sistema, así como lo frágil de los caños de barro por los que se distribuía el agua, no permitieron que el líquido llegara a todas las fuentes. Estos lugares se ubicaron a las afueras de la ciudad, los cuales coinciden con zonas marginadas y de asentamientos poco compactos, como los que se observan en el centro de la ciudad.

No obstante, es un hecho que hubo zonas mucho más cubiertas en el sistema de distribución, que otras. El factor que hemos utilizado, que calcula el número de pobladores de los cuarteles menores entre el número de fuentes, nos permitió determinar diversas zonas de distribución dentro de la ciudad.

${ }^{111}$ La autora de este artículo prepara un libro que amplía la información presentada aquí, además de estudiar la introducción de los pozos artesianos en la ciudad y sus efectos en el crecimiento urbano durante el siglo XIX. 
Las zonas de abundancia también fueron zonas de privilegio social, ya que el número de fuentes privadas era bastante más elevado que el de las públicas. Dado el alto costo de la paja de agua, sólo las personas de mayores recursos económicos pudieron contar con una fuente al interior de sus viviendas. Por el contrario, las zonas de escasez y de carencia total tuvieron un muy limitado, o nulo número de fuentes, tanto públicas como privadas. Los cuarteles menores de esta zona fueron justamente los que tuvieron pocas oportunidades de crecimiento, así como una ocupación dispersa del espacio urbano. Con ello se pone de manifiesto que el agua fue también un factor de diferenciación estamental en la ciudad.

El costo humano que significó transportar agua a las viviendas urbanas puede ser visto también como una carga económica agregada para los habitantes de la ciudad. Sin embargo, las zonas marginales, que contaban con menos fuentes de agua, fueron las que tuvieron que afrontar un mayor costo para allegarse el agua necesaria para cubrir sus necesidades. La zona intermedia o de conexión recibió la visita de aquellos que se encontraban a las afueras de la ciudad. Esta situación ocasionó mayor presión en la demanda de agua de estas fuentes, por lo cual las quejas se multiplicaron notoriamente en fuentes como la de San Sebastián, la Santísima y la Merced. En otros casos, los vecinos tuvieron que acudir a la zona de abundancia. Si bien se pudo mostrar que tener fuentes de agua no aseguraba la llegada del líquido, es un hecho que era más probable que las zonas con mayor número de fuentes pudieran subsanar de mejor manera su demanda de agua.

Hay, sin embargo, muchas preguntas que responder acerca de la supervivencia cotidiana de los habitantes de la ciudad que deberán ser respondidas con estudios posteriores. No obstante, esta nueva lectura del espacio urbano, en que se relaciona el agua con la población, así como la forma de ocupación del espacio urbano, puede dar una nueva perspectiva a la historia 
de las ciudades, pues, como se pudo ver, el agua favoreció o impidió el crecimiento poblacional de las ciudades de Antiguo Régimen. Así mismo, se puede valorar al agua como un factor de diferenciación social, que favoreció a las zonas más antiguas y densamente pobladas de la ciudad, frente a otras marginales y dispersas.

\section{SIGLAS Y REFERENCIAS}

AC Actas de Cabildo.

AGN, OP Archivo General de la Nación, Obras públicas, Ciudad de México, México.

AHCM Archivo Histórico de la Ciudad de México, México.

AHCM, AADR Fondo Ayuntamiento, sección Aguas. Documentos diversos para el arreglo del ramo.

AHCM, AAFP Fondo Ayuntamiento, sección Aguas. Fuentes públicas.

AHCM, AARA Fondo Ayuntamiento, sección Aguas. Ríos y Acequias.

AHCM, AARM Fondo Ayuntamiento, sección Aguas. Reconocimiento de las mercedes de los cuarteles.

AHCM, AASFL Fondo Ayuntamiento, sección Aguas. Santa Fe y Los Leones. AHCM, $A P \quad$ Fondo Ayuntamiento, sección Policía en General.

Cisneros, Diego, Sitio, naturaleza y propiedades de la ciudad de México, México, s/e, 1618.

DÁvalos, Marcela, Los letrados interpretan la ciudad. Los barrios de indios en el umbral de la independencia, México, Instituto Nacional de Antropología e Historia, 2009.

Gaceta de México. Castorena y Ursúa, 1722, Sahagún de Arévalo, 1728-1742, México, Secretaría de Educación Pública, 1950.

García Cubas, Antonio, El libro de mis recuerdos: narraciones históricas, anecdóticas y de costumbres mexicanas anteriores al actual estado social ilustradas con más de trescientos fotograbados, México, Imprenta de Arturo García Cubas, 1904.

Gonzalbo Aizpuru, Pilar, Del barrio a la capital. Tlatelolco y la cindad de México en el siglo XVIII, México, El Colegio de México, 2017. 
Humboldt, Alejandro de, Ensayo político sobre el reino de la Nueva España, México, Porrúa, 1984.

Lafragua, José María, La ciudad de México, México, Porrúa, 2014.

León García, María del Carmen, "Las fuentes de agua y las plazas públicas. Agua potable en la ciudad de México al finalizar el siglo xvıı", en Boletín de Monumentos Históricos, tercera época, 27 (2013), pp. 77-91.

LiRA, Andrés, Comunidades indígenas frente a la ciudad de México. Tenochtitlan y Tlatelolco, sus pueblos y barrios, 1812-1919, México, El Colegio de México, 1995.

Lombardo de Ruiz, Sonia et al., Territorio y demarcación en los censos de población: ciudad de México 1753, 1790, 1848 y 1882, México, Instituto Nacional de Antropología e Historia, Universidad Autónoma de la Ciudad de México, Apoyo al Desarrollo de Archivos y Bibliotecas, Centro de Investigación en Geografía y Geomática “Ing. Jorge I. Tamayo”, 2009.

México dividida en cuarteles mayores y menores: nombres de sus calles: los de sus jueces y alcaldes, $Y$ de los sugetos nombrados por el Superior Gobierno para plantear su nueva Policía en el año de 1811, México, Oficina de don Manuel Antonio Valdés, 1811.

Musset, Alain, El agua en el Valle de México. Siglos XVI-XVIII, México, Pórtico de la Ciudad de México, Centro de Estudios Mexicanos y Centroamericanos, 1992.

Orozco y Berra, Manuel, “La ciudad de México”, en José María Lafragua, La ciudad de México, México, Porrúa, 2014.

Orozco y Berra, Manuel, Memoria para la carta hidrográfica del valle de México, México, Imprenta de A. Boixa a cargo de Miguel Zorñoza, 1864.

OrTIz, Tadeo, México considerado como nación independiente y libre, o sea, algunas indicaciones sobre los deberes más esenciales de los mexicanos, Burdeos, Imprenta de Carlos Lavalle Sobrino, 1832.

Palerm, Jacinta y Carlos Chárrez Araiza, “Medidas antiguas de agua”, en Relaciones. Estudios de Historia y Sociedad, xxIII: 92 (2002), pp. 227-244.

Peñafiel, Antonio, Memoria sobre las aguas potables de la capital de México, México, Oficina Tipográfica de la Secretaría de Fomento, 1884. 
Pineda, Raquel, Origen, vida y muerte del acueducto de Santa Fe, México, Universidad Nacional Autónoma de México, 2000.

Pinto Crespo, Virgilio (dir.), Rafael Gili Ruiz y Fernando Velasco Media, Los viajes de agua de Madrid durante el Antiguo Régimen, Madrid, Fundación Canal, 2010.

Revillagigedo, Conde de, Instrucción reservada que el Conde de Revilla Gigedo dio al sucesor en el mando, Marqués de Branciforte, sobre el gobierno de este continente en el tiempo que fue su virrey, México, Imprenta de la Calle de las Escalerillas, 1830.

Reyna, María del Carmen y Jean-Paul Krammer, Casas y huertas en la Ribera de San Cosme, siglos XVI-XIX, México, Instituto Nacional de Antropología e Historia, 2009.

Rivera y Cambas, Manuel, México pintoresco, artístico y monumental: vistas, descripción, anécdotas y episodios de los lugares más notables de la capital y de los estados, aún de las poblaciones más cortas, pero de importancia geográfica o histórica, México, Imprenta de la Reforma, 1880, vol. 1.

Romero de Terreros, Manuel, Fuentes virreinales, México, Universidad Nacional Autónoma de México, 1966.

VIERA, Juan de, Breve y compendiosa narración de la ciudad de México (edición facsimilar), $1^{a}$ ed. 1777, México, Instituto José María Luis Mora, 1992. 